\title{
Tailored nanocarriers for the pulmonary delivery of levofloxacin against Pseudomonas aeruginosa: a comparative study
}

Rabeb Mouna Derbali ${ }^{\mathrm{a}, \mathrm{b}}$, Valery Aoun ${ }^{\mathrm{a}, \mathrm{b}}$, Ghina Moussa ${ }^{\mathrm{a}}$, Giorgia Frei ${ }^{\mathrm{a}}$, Soudeh F. Tehrani $^{\mathrm{b}}$, Juliana Campos Del'Orto ${ }^{\mathrm{a}, \mathrm{c}}$, Patrice Hildgen ${ }^{\mathrm{c}}$, V. Gaëlle Roullin ${ }^{\mathrm{b} *}$, Jeanne Leblond Chain $^{\mathrm{a}^{*}}$

a Gene Delivery Laboratory, Faculty of Pharmacy, Université de Montréal, PO Box 6128, Downtown station, Montréal, QC, H3T 1J4, Canada.

${ }^{\mathrm{b}}$ Pharmaceutical Nanotechnologies Laboratory, Faculty of Pharmacy, Université de Montréal, PO Box 6128, Downtown station Montréal, QC, H3T 1J4, Canada.

${ }^{c}$ Faculty of Pharmacy, Université de Montréal, PO Box 6128, Downtown station Montréal, QC, H3T 1J4, Canada.

* Co-corresponding author at: Gene Delivery Laboratory, Faculty of Pharmacy, University of Montréal, PO Box 6128, Downtown station, Montréal, QC, H3T 1J4, Canada.vg.roullin@umontreal.ca; jeanne.leblond-chain@umontreal.ca, phone +1-514$343-6455$ fax +1-514-343-2102 


\begin{abstract}
Cystic fibrosis (CF) patients are faced with chronic bacterial infections displaying persistent resistance if not eradicated during the first stage of the disease. Nanoantibiotics for pulmonary administration, such as liposomal ciprofloxacin or amikacin, have progressed through clinics thanks to their sustained release, prolonged lung residence time and low systemic absorption. In this work, we sought a nanoformulation of levofloxacin for the treatment of Pseudomonas aeruginosa. We prepared and compared PLA- $g$-PEG nanoparticles, as well as anionic and cationic liposomes for their size, charge and encapsulation efficiency. Cationic liposomes were unable to encapsulate any drug and were subsequently considered as a control formulation. Regarding the efficiency of the nanocarrier, anionic liposomes exhibited a prolonged release over $72 \mathrm{~h}$ and preserved the antibacterial activity of levofloxacin against 5 strains of Pseudomonas aeruginosa, whereas polymeric nanoparticles quickly released their entire payload and increased the minimal inhibitory concentration (MIC) of levofloxacin. Thus, only anionic liposomes were considered for further preclinical development. Anionic liposomes exhibited a suitable colloidal stability by Turbiscan analysis and crossed a layer of artificial mucus in under one hour in a Transwell setup. Despite their negative surface charge, liposomes still interacted with $P$. aeruginosa membrane in a dose-reponse manner, as demonstrated by flow cytometry. Viability assays confirmed that anionic liposomes, loaded or not, exhibited a good safety profile on A549 epithelial cells even at high concentrations. Finally, nebulization of anionic liposomes containing levofloxacin did not impact their colloidal stability and the droplet size distribution was suitable for deep lung deposition, where $P$. aeruginosa infection lies. Therefore, levofloxacin-loaded anionic liposomes exhibited suitable properties for the pulmonary treatment of $P$. aeruginosa in CF. This step-by-step study confirms the promising role of liposomes for lung administration of antibiotics, as recently seen in clinics, and fosters their development for several types of antibiotics.
\end{abstract}

\title{
Keywords
}

Liposomes; levofloxacin; polymeric nanoparticles; Pseudomonas aeruginosa; mucus penetration; lung delivery 


\section{Introduction}

Cystic fibrosis is a genetic disorder caused by a mutation in the gene coding for the ubiquitous transmembrane conductance regulator (CFTR) protein in epithelial cells. It occurs in 0.8 out of 10,000 live births in Western countries ${ }^{1}$. Because more than 1,900 mutations have been identified to date in the CFTR gene ${ }^{2}$, curative treatments remain difficult to foresee. One of the major symptoms of cystic fibrosis (CF) is the development of a thick and viscous mucus in the airways. Plagued by a low mucociliary clearance, this environment is particularly favorable for bacterial infections ${ }^{3}$. Pseudomonas aeruginosa, a gram-negative bacterium, infects $80 \%$ of adult $\mathrm{CF}$ patients ${ }^{4}$ and is a major predictor of mortality ${ }^{5,6}$. Therefore, antibiotic treatment of $P$. aeruginosa infections is a cornerstone of cystic fibrosis therapy ${ }^{7}$. The recommended treatment for $P$. aeruginosa infections consists of pulmonary and/or oral administration of one or two antibiotics several times a day over a period of several months ${ }^{8}$. This regimen significantly reduces the quality of life of CF patients, as well as their adherence to treatment ${ }^{9}$. As fewer and fewer new antibacterial agents are developed through current medicinal chemistry strategies, optimizing the formulation of existing drugs has emerged as a relevant approach to improve the efficacy of antibiotics ${ }^{10}$.

Nanoantibiotics have recently emerged as a promising technology to improve outcomes of chronic lung infections. Drug nanocrystals, stabilized either by polymers ${ }^{11}$ or lipids $^{12}$, have demonstrated good inhibition of the P. aeruginosa virulence factor, as well as a good tolerance in vivo ${ }^{11}$. Polymeric nanoparticles, based on chitosan ${ }^{13}$ or poly(lactic-coglycolic acid) (PLGA), have recently been investigated for the delivery of ciprofloxacin $^{14}$, levofloxacin ${ }^{15,16}$, and cationic antimicrobial peptides ${ }^{17}$. However, liposomes have been by far the most investigated carriers for the pulmonary delivery of antibiotics, including tobramycin ${ }^{18,19}$, polymixin $\mathrm{B}^{20}$, amikacin $^{21}$ and clarithromycin ${ }^{22}$. Their intrinsic biocompatibility, biodegradability, and ability to encapsulate both hydrophilic and hydrophobic drugs, as well as their easy-to-modify surfaces, make them excellent candidates for clinical applications. Recent Phase III clinical results of Arikace ${ }^{\mathrm{TM}}$, a liposomal formulation of amikacin, have shown that a once-a-day administration of these amikacin-loaded liposomes was as efficient as the current twicea-day tobramycin treatment for $\mathrm{CF}$ patients ${ }^{23}$. Liposomal ciprofloxacin (Pulmaquin $®$ and 
Lipoquin $\left({ }^{\circledR}\right)$ has also reached phase IIb clinical trials for the treatment of $P$. aeruginosa infections in CF patients, demonstrating a significant decrease in bacterial load and an improvement of lung function after a 14 days treatment ${ }^{24}$. Compared to the free drug inhalation, the advantages of such nanosystems are attributed to the sustained release of the drug in the lungs, the limited systemic exposure and the improved mucus penetration ability $^{25}$. Such a success fostered the development of liposomes for pulmonary administration of additional antibiotics, such as levofloxacin. Indeed, this fluoroquinolone has shown promising results for inhaled therapy in clinical trials for nonCF patients (Aeroquin $\left.{ }^{\circledR}\right)^{26}$. Conversely, CF patients did not show any improvement, highlighting the impact of the thick mucus layer characteristic of $\mathrm{CF}$ as a delivery barrier against levofloxacin efficiency ${ }^{7}$. Therefore, improving its delivery would empower its therapeutic efficiency for CF patients. Levofloxacin has already been encapsulated into chitosan nanoparticles ${ }^{27}$, hybrid lipid-polymer nanoparticles ${ }^{15}$, niosomes ${ }^{28}$, solid lipid microparticles ${ }^{29}$ and liposomes ${ }^{30}$ and conjugated to gold nanoparticles ${ }^{31}$, but its in vitro antibacterial activity against $P$. aeruginosa has shown mitigated results ${ }^{30}$. The encapsulation of levofloxacin in liposomes has also been envisioned for the treatment of pulmonary inflammation ${ }^{32}$, ocular antibiotic delivery ${ }^{33,34}$ and antituberculosis treatment ${ }^{35}$ but, to the best of our knowledge, it has never been optimized for pulmonary antibiotic treatment.

Hence, in this work, we sought a nanoformulation for levofloxacin. We compared liposomes, which have shown recent success in clinics for ciprofloxacin (Pulmaquin ${ }^{\circledR}$ ) and amikacin (Arikace ${ }^{\mathrm{TM}}$ ), with polymeric nanoparticles composed of PLA-PEG, also tested in clinics ${ }^{36}$ and which we previously reported for pulmonary administration of antifungals ${ }^{37,38}$. Comparison was first based on physicochemical properties and encapsulation efficiency. Then, the nanocarrier efficacy was evaluated through release profile and antimicrobial activity. Finally, the stability and penetration in mucus, interaction with the bacteria, biocompatibility with epithelial cells and aerosolization capability were assessed to ensure the feasibility of this nanoformulation for pulmonary administration.

\section{Experimental Section}




\section{Materials}

Levofloxacin was purchased from Alfa Aesar (Ward Hill, MA). 1,2-distearoyl-snglycero-3-phosphocholine (DSPC) and 1,2-distearoyl-sn-glycero-3phosphoethanolamine-N-(polyethylene-glycol)-2000 (DSPE- $\mathrm{PEG}_{2000}$ ) were obtained from Avanti Polar Lipids (Alabaster, AL). Spectra/Por® molecular porous membrane tubing MWCO 6-8000 was purchased from Spectrum Laboratories Inc. (Rancho Dominguez, CA). Phosphorus standard solution $0.65 \mathrm{mM}$ (phosphorus as $\mathrm{KH}_{2} \mathrm{PO}_{4} 20$ $\mu \mathrm{g} / \mathrm{mL}$ in $0.05 \mathrm{~N} \mathrm{HCl}$ ), ammonium molybdate, ammonium sulfate, sodium metabisulfide, ascorbic acid, sulfuric acid, hydrogen peroxide, sodium chloride, cholesterol, other chemicals and synthesis-grade solvents were purchased from Sigma Aldrich (Oakville, ON, Canada). Chemicals and solvents were used without further purification.

\section{Liposome preparation}

Anionic liposomes were composed of DSPC/Cholesterol/DSPE-PEG 2000 (55:40:5 mol\%) and cationic liposomes were composed of DOTAP/Cholesterol (50:50 mol\%). The liposomes were prepared by hydration of a lipid film. Lipids (final lipid concentration 4$15 \mathrm{mM}$ ) were mixed in chloroform and evaporated at $40^{\circ} \mathrm{C}$ under reduced pressure (15 mbar) for $1 \mathrm{~h}$. The lipid film was rehydrated with $1 \mathrm{~mL}$ of ammonium sulfate solution (300 $\mathrm{mM}$ in water) for anionic liposomes and $1 \mathrm{~mL}$ of a solution of $5 \%$ dextrose and 5 $\mathrm{mM} \mathrm{NaCl}$ for cationic liposomes. After $1 \mathrm{~h}$ of gentle stirring at $70{ }^{\circ} \mathrm{C}$, the suspension was sequentially extruded through 400-, 200- and 100-nm polycarbonate membranes (Avestin, Ottawa, ON) using a manual mini-extruder (Avanti Polar Lipids Inc., Alabaster, $\mathrm{AL}$ ). The anionic liposome suspension was diluted 1:4 in $180 \mathrm{mM} \mathrm{NaCl}$ and dialysed against $1 \mathrm{~L}$ of $180 \mathrm{mM} \mathrm{NaCl}$ for $18 \mathrm{~h}$ to remove ammonium sulfate external medium. Levofloxacin-loaded liposomes were prepared by incubating a levofloxacin stock solution (40 mg/mL in $1 \% \mathrm{v} / \mathrm{v}$ acetic acid) with dialyzed liposomes (1:3 v/v) under continuous stirring $\left(60 \mathrm{rpm}, 70^{\circ} \mathrm{C}, 40 \mathrm{~min}\right)$. Non-encapsulated levofloxacin was removed through a Sephadex G-50 column equilibrated with $180 \mathrm{mM} \mathrm{NaCl}$. Liposome-containing fractions were pooled and checked for phospholipid content using a Bartlett assay ${ }^{39}$. Encapsulated amount of levofloxacin was determined by HPLC after rupture of the liposome suspension in methanol $(1: 9,1 \mathrm{~mL})$. Liposomes were stored in the dark at $4^{\circ} \mathrm{C}$. 
Fluorescent liposomes were obtained by including $0.05 \%$ of Liss-Rhodamine-PE (AvantiPolar Lipids, Alabaster, AL) in the lipid composition.

\section{Polymeric nanoparticle preparation}

PEG- $g$-PLA polymer was synthesized and characterized $\left(M_{w}=20,100 \mathrm{~g} / \mathrm{mol}, \mathrm{M}_{\mathrm{n}}=\right.$ $13,400 \mathrm{~g} / \mathrm{mol}$, Polydispersity index $=1.5$ by GPC, $6.1 \mathrm{~mol} \%$ PEG grafted by ${ }^{1} \mathrm{H}$ NMR) as previously described ${ }^{38}$. Polymeric nanoparticles were prepared using an emulsionsolvent evaporation method. Briefly, polymer ( $1 \mathrm{~g}$ in $35 \mathrm{~mL}$ of dichloromethane) with or without levofloxacin (drug-to-polymer ratio 1:1.5 w/w) was emulsified in a polyvinyl alcohol (PVA) aqueous solution $(0.5 \% \mathrm{w} / \mathrm{v}, 100 \mathrm{~mL})$ at a pressure of 10,000 psi for $5 \mathrm{~min}$ (Emulsiflex C30, Avestin, Ottawa, ON). After solvent evaporation, the suspension was purified by 4 cycles of centrifugation $\left(41,340 \mathrm{~g}, 1 \mathrm{~h}, 4^{\circ} \mathrm{C}\right)$, resuspended in distilled water, then lyophilized and stored at $4{ }^{\circ} \mathrm{C}$. For encapsulation efficiency determination, levofloxacin was extracted from nanoparticles by dissolving freeze-dried nanoparticles (5 $\mathrm{mg}$ ) in chloroform (1 mL, RT, $1 \mathrm{~h})$. After partial solvent evaporation under nitrogen flow, the residue was extracted into the HPLC mobile phase.

\section{High Performance Liquid chromatography (HPLC) and drug loading efficiency}

The HPLC instrumentation consisted of Agilent 1200 Series system equipped with an ultraviolet detector (Agilent, Mississauga, ON) and a C18 Zorbax 300SB column (4.6 $\mathrm{mm} \times 150 \mathrm{~mm}, 5 \mu \mathrm{m}$, GL sciences, Japan). Column temperature was set at $50{ }^{\circ} \mathrm{C}$. The mobile phase A consisted of $5 \mathrm{mM}$ ammonium acetate with $0.1 \%$ trifluoroacetic acid (TFA) and the mobile phase B was acetonitrile with $0.1 \%$ TFA. Gradient elution : 10$100 \% \mathrm{~B}$ in $3 \mathrm{~min}$ then $3 \mathrm{~min}$ isocratic at 100\% A. Run time: 6 min. Flow rate: 0.75 $\mathrm{mL} \cdot \min ^{-1}$. UV detection: $294 \mathrm{~nm}$. Injection volume: $15 \mu \mathrm{L}$. For the calibration curve, levofloxacin standard solutions $\left(0.5-100 \mu \mathrm{g} \cdot \mathrm{mL}^{-1}\right)$ were prepared in Milli-Q $\mathrm{H}_{2} \mathrm{O}$. Injections were performed in triplicate for each condition. Encapsulation efficiency (EE\%) and drug loading (DL\%) were determined using the following equations:

$$
E E \%=\frac{\text { Mass of encapsulated levofloxacin }}{\text { Mass of initial levofloxacin }} \times 100
$$




$$
D L \%=\frac{\text { Mass of encapsulated levofloxacin }}{\text { Mass of final formulation (lipids }+ \text { levofloxacin) }} \times 100
$$

EE\% and DL\% were calculated as the mean of three independent experiments with three batches of polymeric nanoparticles or anionic liposomes.

\section{Physicochemical characterization}

The average hydrodynamic diameters $\left(\mathrm{D}_{\mathrm{H}}\right)$, polydispersity indexes $(\mathrm{PdI})$ and zeta potentials $(\zeta \mathrm{P})$ were measured using dynamic light scattering (Zetasizer Nano Zs, Malvern Instruments, Worcestershire, UK). Samples were prepared by suspending $10 \mu \mathrm{L}$ of liposomes or $5 \mathrm{mg}$ of freeze-dried nanoparticles in $1 \mathrm{~mL}$ of Milli-Q water. Each measurement was recorded in triplicate $\left(\mathrm{D}_{\mathrm{H}}: 25^{\circ} \mathrm{C}\right.$, scattering angle of $173^{\circ}, \zeta \mathrm{P}: 20^{\circ} \mathrm{C}$, $150 \mathrm{~V})$, and water was used as a reference medium.

\section{In vitro drug release}

Levofloxacin, levofloxacin-loaded nanoparticles or anionic liposomes (all equivalent to $200 \mu \mathrm{g}$ initial levofloxacin) were suspended in PBS (10 mM, pH 7.4, $2 \mathrm{~mL}$ ) and dialyzed against 1 L of PBS (Spectra Por 1, MWCO: 6-8 kDa, Spectrum Lab, CA). At predetermined time intervals $(5,10,15,30 \mathrm{~min}, 1,2,3,12,24,48,72 \mathrm{~h}), 1 \mathrm{~mL}$ of the external media was withdrawn for HPLC analysis and replaced with fresh buffer. The released levofloxacin $(\%)$ was calculated as the cumulative amount of levofloxacin measured as compared to the initial amount of levofloxacin in the dialysis bag (200 $\mu \mathrm{g}$ initial levofloxacin). All experiments were run in triplicate.

\section{Antibacterial Minimal Inhibitory Concentration (MIC)}

Two Mucoid (M-01, M-02) and two non-mucoid (NM-01, NM-02) species of Pseudomonas aeruginosa strains were isolated by Dr. Valerie Waters and Dr. Yvonne Yan from the bronchoalveolar lavage fluids of cystic fibrosis patients and identified at the SickKids Hospital in Toronto. Quality control strain was P. aeruginosa ATCC 27853 (American Type Culture Collection, Rockville, USA).

The American reference protocol M07-A2 from the Clinical and Laboratory Standards Institute (CLSI), was adapted for the use of nanosuspensions ${ }^{40}$. All strains were routinely grown at $37^{\circ} \mathrm{C}$ in Cation Adjusted Mueller Hinton Broth (CAMBH, Sigma Aldrich, 
Oakville, ON). They were seeded at $0.5-2.5 \times 10^{6} \mathrm{CFU} \cdot \mathrm{mL}^{-1}$ in $\mathrm{CAMBH}$ and plated in a 96-well plate (50 $\mu \mathrm{L} /$ well). $50 \mu \mathrm{L}$ of levofloxacin nanoparticles or anionic liposomes $(0.31-16 \mu \mathrm{g} / \mathrm{mL})$ were added and incubated for $24 \mathrm{~h}$ or $48 \mathrm{~h}$ at $37^{\circ} \mathrm{C}$. The bacteria viability was assessed by addition of resazurin solution (AlamarBlue ${ }^{\circledR}$, ThermoFisher, Montréal, QC, $700 \mu \mathrm{M}$ in water, $10 \mu \mathrm{L} /$ well) in each well. After $4 \mathrm{~h}$ at $37^{\circ} \mathrm{C}$, the absorbance of each well was measured at 570 and $600 \mathrm{~nm}$ (Safire, Tecan, Switzerland). Bacteria viability was normalized relatively to the negative control (untreated bacteria) and calculated as followed.

$$
\% \text { cell viability }=\frac{\left(\varepsilon_{600} A_{570}-\varepsilon_{570} A_{600}\right) \text { Treated cells }}{\left(\varepsilon_{600} A_{570}-\varepsilon_{570} A_{600}\right) \text { Untreated cells }} \times 100
$$

The Minimum Inhibitory Concentration (MIC) was determined as the lowest concentration inhibiting $100 \%$ of microorganism growth compared to the growth of the untreated controls. To confirm the test validity, the MICs obtained for the reference strain were compared to those obtained by the CLSI protocol ${ }^{40}$. All experiments were run in triplicate for each strain (three independent replicates with three wells/condition).

\section{Liposome stability in mucus}

The behavior of liposomes in the presence of mucus was assessed by colloidal kinetics using the Static Multiple Light Scattering (MSLS) technique ${ }^{41}$. Briefly, cationic or anionic liposomes $(0.5 \mathrm{~mL}, 6.9 \mathrm{mM})$ were placed in $20 \mathrm{~mL}$ of either phosphate buffer solution $(\mathrm{pH}=7.4)$, Simulated Interstitial Lung Fluid $(\mathrm{SILF})^{42}$ or artificial mucus. SILF was prepared with $17 \mathrm{mg} \mathrm{MgCl}_{2} \cdot 6 \mathrm{H}_{2} \mathrm{O}, 594 \mathrm{mg} \mathrm{NaCl}, 36 \mathrm{mg} \mathrm{KCl}, 15 \mathrm{mg} \mathrm{Na} \mathrm{HPO}_{4}, 6.7$ $\mathrm{mg} \mathrm{NaSO}$, $35 \mathrm{mg} \mathrm{CaCl} 2 \cdot 2 \mathrm{H}_{2} \mathrm{O}, 96 \mathrm{mg} \mathrm{CH} \mathrm{COONa}_{3} 3 \mathrm{H}_{2} \mathrm{O}, 262 \mathrm{mg} \mathrm{NaHCO}$ and $8 \mathrm{mg}$ sodium citrate dihydrate in $100 \mathrm{~mL}$ of Milli-Q water $(\mathrm{pH} 7.4)^{42}$. Artificial mucus was prepared by mixing $250 \mu \mathrm{L}$ of sterile egg yolk emulsion, $250 \mathrm{mg}$ mucin, $0.4 \mathrm{mg}$ DTPA, $250 \mathrm{mg} \mathrm{NaCl}, 110 \mathrm{mg} \mathrm{KCl}, 1 \mathrm{~mL}$ of RPMI and $50 \mathrm{~mL}$ of water ${ }^{17}$. The samples were placed in the Turbiscan Instrument (Turbiscan, Formulaction, France). During a 20-min incubation at $37^{\circ} \mathrm{C}$, they were scanned by a light beam emitted at a near infrared wavelength $(880 \mathrm{~nm})$ every $30 \mathrm{~s}$. Two synchronous optical sensors received, respectively, light transmitted through the sample and light backscattered by the sample. The 
Turbiscan Index (TSI) was used to evaluate the variation of mean particle size and their volume fraction, as described: ${ }^{43}$

$$
T S I=\sum_{0}^{i}\left|\operatorname{scan}_{r e f}\left(h_{j}\right)-\operatorname{scan}_{i}\left(h_{j}\right)\right|
$$

where $\operatorname{scan}_{\text {ref }}$ is the initial backscattering value and $\operatorname{scan}_{i}$ is the backscattering value at a given time $\mathrm{i}, \mathrm{h}_{\mathrm{j}}$ is a given height in the measuring cell and TSI is the Turbiscan Index, a destabilization factor, i.e. the summation of all scan differences from the bottom to the top of the vial at a given time $\mathrm{i}$.

\section{Diffusion through artificial mucus}

The diffusion through mucus was inspired from the method of Friedl et al. ${ }^{44}$ adapted by Angelo et al. ${ }^{17}$. Briefly, $75 \mu \mathrm{L}$ of artificial mucus was spread onto the filters of a 24 -well Transwell system (internal diameter $6.5 \mathrm{~mm}$; pore size $8 \mu \mathrm{m}$, Costar®, Corning, Tewksbury, MA). As a positive control, no mucus was placed on the donor side of the wells. The receiver compartments were filled with $300 \mu \mathrm{L}$ SILF. Tested formulations were then deposited on the donor side $(100 \mu \mathrm{L})$. Fluorescent anionic liposomes $(1$ $\mathrm{mg} / \mathrm{mL})$ were compared to cationic liposomes $(1 \mathrm{mg} / \mathrm{mL})$, used as a control known to be trapped in the mucus ${ }^{45}$. At each time point (5, 20, 30 min, 1, 2, 3, 4, 5, 24, $\left.48 \mathrm{~h}\right), 25 \mu \mathrm{L}$ was sampled from the receiver media and replaced with fresh SILF. Samples were analyzed for their fluorescent content after dilution with $125 \mu \mathrm{L}$ SILF (Safire, Tecan, Switzerland). $\lambda_{\text {ex/em }}$ were adjusted for fluorescent liposomes $(560 / 585 \mathrm{~nm})$. The diffusion of particles $(\%)$ was expressed as the percentage of the fluorescence recovered in the receptor as compared to the maximum fluorescence recovered in the donor compartment when no mucus was present (positive control). All experiments were run in triplicate.

\section{Interaction with Pseudomonas aeruginosa}

Liposome interaction with Pseudomonas aeruginosa was observed by flow cytometry. $P$. aeruginosa (ATCC 27853) was grown overnight $\left(37^{\circ} \mathrm{C}, 24 \mathrm{~h}\right)$ in Soybean casein digest agar Broth (E\&O Laboratories, Bonnybridge, Scotland). After $24 \mathrm{~h}$, the bacteria were counted by optical density every day until reaching a concentration of approximately $5 \times$ $10^{7}$ colony forming units $(\mathrm{CFU} / \mathrm{mL})$. The bacteria $\left(5 \times 10^{7} \mathrm{CFU} / \mathrm{mL}\right)$ were incubated with 
fluorescent liposomes at increasing concentrations $(67,667,6667 \mu \mathrm{g} / \mathrm{mL}$, doses equivalent to those required for 8,80 and $800 \mu \mathrm{g} / \mathrm{mL}$ of levofloxacin). After $4 \mathrm{~h}$ at $37{ }^{\circ} \mathrm{C}$, samples were diluted 1:2 in PBS and analyzed by flow cytometry (FACS Calibur ${ }^{\mathrm{TM}}$, BD Biosciences, San Jose, CA). The results were analyzed using FlowJo software (vX.0.7, Ashland, OR, USA) and reported either as the mean fluorescent intensity normalized to mode, i.e. as a percentage of the maximum fluorescence intensity (Figure 3); either as the percentage of $P$. aeruginosa positive to rhodamine (Supporting information). Negative control was untreated bacteria and positive control was cationic liposomes at the same concentrations. All the experiments were realized in triplicate.

\section{Cell viability}

Adenocarcinomic human alveolar basal epithelial cells A549 (ATCC® CCL-185 ${ }^{\mathrm{TM}}$ ) were cultured in DMEM medium supplemented with $4.5 \mathrm{~g} / \mathrm{L}$ glucose and L-glutamine, without sodium pyruvate, with $10 \%$ Bovine Calf Serum. The cells were incubated in a humidified atmosphere at $37{ }^{\circ} \mathrm{C}, 5 \% \mathrm{CO}_{2}$ and sub-cultured at $80 \%$ confluency. A549 cells were seeded one day before each experiment on a 96-well plate at an approximate density of 5000 cells per well. Cytotoxicity of the anionic and cationic liposomes, with or without levofloxacin, was evaluated using a resazurin-based cell viability assay, similar to the MIC assay. A549 were exposed to increasing concentrations of liposomes or free levofloxacin (200 $\mu \mathrm{L}$ final volume/well). After $48 \mathrm{~h}$ incubation, cells were washed with PBS. The cell viability was assessed by addition of $100 \mu \mathrm{L}$ of resazurin solution $(44 \mu \mathrm{M}$ in PBS from a stock solution of $440 \mu \mathrm{M}$ in DMEM) in each well. After $24 \mathrm{~h}$, the absorbance of each well was measured at 570 and $600 \mathrm{~nm}$. Cellular viability was normalized relative to the negative control (cells treated with 5\% dextrose) and calculated as described in the MIC section.

\section{Nebulization properties}

In vitro nebulization properties were evaluated using the Next Generation Cascade Impactor (NGI, Copley Scientific, Nottingham, UK). Experimental parameters were adapted from the USP chapter <1601> and European Committee for Standardization methodology $y^{46}$. The setup is shown in Figure S7. A simplified setup was designed to 
monitor the behavior of the nanosized liposomes throughout nebulization (Figure S7). To maximize the recovery volume, a vacuum adapter was connected to the receiving flask, with both the nebulizer and the vacuum pump. Particle size and polydispersity index were measured before and after nebulization by dynamic light scattering (DLS).

For lung distribution, $5 \mathrm{~mL}$ of the levofloxacin solution $(2.47 \mathrm{mg})$, either free or encapsulated into anionic liposomes, was placed in the jet nebulizer (Salter Labs, Arvin, CA) coupled to nitrogen gas at 10 psi to generate a drug mist at 10 psi. This mist was carried out by a breathing pattern set at 14 breaths per minute and $240 \mathrm{~mL} / \mathrm{breath}$ with BRS 1000 Breath Simulator (Copley Scientific, Nottingham, UK). At the NGI entry, the vacuum system allowed drop impaction at a $14 \mathrm{~L} / \mathrm{min}$ airflow monitored by an airflow meter (high capacity pump model and airflow meter, Copley Scientific, Nottingham, UK). NGI was kept at $6{ }^{\circ} \mathrm{C}$ inside NGI Cooler (Copley Scientific, Nottingham, UK). Cups were pre-coated with a thin layer of silicon to prevent particle bouncing. After 40 min nebulization, samples were recovered from the cups and the exit filter using $3 \mathrm{~mL}$ of $1 \% \mathrm{v} / \mathrm{v}$ acetic acid. The levofloxacin amount remaining in the nebulizer chamber was similarly recovered. Samples were then freeze-dried overnight (Modulyo Freeze Dryer, Fisher Electron Corporation, Massachusetts, USA) followed by solubilization in $1 \% \mathrm{v} / \mathrm{v}$ acetic acid:MeOH $(100 \mu \mathrm{L})$ enabling levofloxacin dosing by HPLC as described above. Concentrations were translated in mass deposition allowing a comparison between free and liposomal levofloxacin. Three determinations were made for each solution. Emitted dose (ED) was estimated as the difference between the total drug amount initially added to the nebulizer and the amount remaining after 40 minutes of nebulization. Deposition patterns were represented as a percentage of total recovered levofloxacin. The cumulative mass versus the logarithmic cutoff diameter of consecutive stages was plotted and used to determine the mass median aerodynamic diameter (MMAD) and the geometric standard deviation (GSD). MMAD is defined as the particle size at which $50 \%$ of the drug amount was deposited. GSD $=(\text { Size } \mathrm{x} / \text { Size } \mathrm{y})^{1 / 2}($ where $\mathrm{x}=$ size for $84 \%$ of deposition, $\mathrm{y}=$ size for $16 \%$ of the deposition). The fine particle fraction (FPF) and respirable fraction (RF) were calculated for particles $<6 \mu \mathrm{m}$ as:

$\mathrm{FPF}(\%)=\frac{\sum \text { Levofloxacin mass recovered from cups } 3 \text { to } 7}{\text { Levofloxacin mass initially introduced in nebulizer }} \times 100$ 
$\mathrm{RF}(\%)=\frac{\sum \text { Levofloxacin mass recovered from cups } 3 \text { to } 7}{\sum \text { Levofloxacin mass recovered from cups } 1 \text { to } 7} \times 100$

\section{Statistical analysis}

Statistical analysis was carried out using PRISM 6.01 software (Graphpad, CA, USA). For flow cytometry quantification, statistical analysis was performed using a one-way analysis of variance (ANOVA) and $p$ values were adjusted for multiple comparisons using the Bonferroni correction. For cell viability and nebulization properties, statistical analysis was performed using multiple t-tests and statistical significance was determined using the Holm-Sidak method. ** $\mathrm{p}<0.01$, *** $\mathrm{p}<0.001$.

\section{Results and discussion}

\section{Nanocarrier design for levofloxacin encapsulation}

The amphipathic nature of levofloxacin, exhibiting a $\log \mathrm{P}$ from -2 to $0.3^{47}$, should allow its potential encapsulation in liposomes as well as in polymeric nanoparticles. Hence, we compared its encapsulation in both previously reported nanosystems, which were readily accessible and already tested in clinical trials for various therapeutic applications. To achieve core-shell polymeric nanoparticles, poly(lactic acid)-grafted-poly(ethylene glycol) (PLA-g-PEG) was selected due to its excellent biodegradability and biocompatibility $^{48}$. Our previous reports showed good encapsulation efficiencies for antifungal $^{37}$ and anti-inflammatory drugs ${ }^{49}$, as well as suitable pulmonary deposition ${ }^{38}$ and stealth properties ${ }^{48}$. Levofloxacin encapsulation was achieved by the emulsionsolvent evaporation method. We also prepared anionic liposomes with DSPC, cholesterol and DSPE-PEG $2000(55: 40: 5 \mathrm{~mol} \%)$, a composition similar to the clinical composition of Arikace ${ }^{\mathrm{TM}}{ }^{21}$ and Lipoquin $\AA^{24}$. These lipids are known for their biocompatibility, colloidal stability, and limited drug leakage ${ }^{33,47}$. Finally, we compared these formulations with a cationic formulation composed of DOTAP/Cholesterol (50:50 mol\%). Cationic liposomes have been widely reported for inhaled gene therapy, and have reached phase IIb clinical trials as a treatment for $\mathrm{CF}^{50}$. Liposomes were prepared by hydration of a lipid film, and the ammonium sulfate gradient technique was used to optimize levofloxacin encapsulation $^{32}$. 
Table 1. Physicochemical characterization of purified PLA- $g$-PEG nanoparticles, anionic and cationic liposomes used in this study. N/A : not applicable.

\begin{tabular}{|c|c|c|c|c|c|c|}
\hline Formulation & Drug & $\begin{array}{c}\mathrm{D}_{\mathrm{H}} \pm \mathrm{SD} \\
(\mathrm{nm})\end{array}$ & $\mathrm{PdI} \pm \mathrm{SD}$ & $\begin{array}{c}\zeta \mathrm{P} \pm \mathrm{SD} \\
(\mathrm{mV})\end{array}$ & $\begin{array}{l}\mathrm{DL} \pm \mathrm{SD} \\
(\% \mathrm{w} / \mathrm{w})\end{array}$ & $\begin{array}{l}\mathrm{EE} \pm \mathrm{SD} \\
(\% \mathrm{w} / \mathrm{w})\end{array}$ \\
\hline \multirow[t]{2}{*}{ PLA- $g$-PEG nanoparticles } & - & $151 \pm 1$ & $0.13 \pm 0.01$ & $-6.3 \pm 1.2$ & N/A & N/A \\
\hline & Levo & $151 \pm 1$ & $0.13 \pm 0.03$ & $-1.2 \pm 1.0$ & $1.42 \pm 0.04$ & $6.15 \pm 0.16$ \\
\hline \multirow[t]{3}{*}{ Anionic liposomes } & - & $143 \pm 1$ & $0.05 \pm 0.02$ & $-8.8 \pm 0.8$ & N/A & N/A \\
\hline & Levo & $160 \pm 6$ & $0.05 \pm 0.03$ & $-7.9 \pm 0.6$ & $6.72 \pm 0.73$ & $11.91 \pm 3.43$ \\
\hline & Rho & $161 \pm 1$ & $0.04 \pm 0.02$ & $-6.5 \pm 0.1$ & N/A & N/A \\
\hline $48 h$ in artificial mисиs & Rho & $159^{\mathrm{b}} \pm 12$ & $0.58 \pm 0.09$ & $-10.9 \pm 1.1$ & N/A & N/A \\
\hline \multirow[t]{3}{*}{ Cationic liposomes } & - & $137 \pm 2$ & $0.04 \pm 0.02$ & $+31.6 \pm 13.5$ & $\mathrm{~N} \backslash \mathrm{A}$ & $\mathrm{N} \backslash \mathrm{A}$ \\
\hline & Levo & $125 \pm 3$ & $0.05 \pm 0.01$ & $+19.5 \pm 7.4$ & $<0.82^{\mathrm{c}}$ & $<0.11^{\mathrm{c}}$ \\
\hline & Rho & $127 \pm 2$ & $0.05 \pm 0.01$ & $+30.3 \pm 0.6$ & N/A & N/A \\
\hline $48 h$ in artificial тисиs & Rho & $503^{\mathrm{b}} \pm 12$ & $0.42 \pm 0.01$ & $-10.6 \pm 0.4$ & N/A & N/A \\
\hline
\end{tabular}

$\mathrm{D}_{\mathrm{H}}$ : hydrodynamic diameter ; Levo: loaded with levofloxacin; Rho: loaded with rhodamine.

${ }^{\mathrm{b}}$ Mean value of the major peak, since micrometer aggregates were detected.

${ }^{\mathrm{c}}$ The levofloxacin concentration was below the quantification limit by HPLC $(5 \mu \mathrm{g} / \mathrm{mL})$. The maximum values have been calculated using $5 \mu \mathrm{g} / \mathrm{mL}$.

The three different formulations displayed similar physicochemical properties (Table 1). Whether loaded with levofloxacin or not, all formulations exhibited hydrodynamic diameters below $200 \mathrm{~nm}$, with a narrow size distribution. Polymeric nanoparticles and anionic liposomes displayed similar zeta potential, slightly negative. These properties were in line with $\mathrm{CF}$ mucus-penetrating requirements ${ }^{51}$. Conversely, cationic liposomes displayed a positive zeta potential, in agreement with previous literature ${ }^{45}$. Unfortunately, the cationic liposomes were unable to encapsulate levofloxacin, either by hydration with levofloxacin solution or by ammonium sulfate gradient. In both cases, the amount of encapsulated levofloxacin was below the detection limit $(5 \mu \mathrm{g} / \mathrm{mL}$, by HPLC) after purification. Therefore, cationic liposomes were not considered as a suitable formulation for levofloxacin. Cationic liposomes have been reported for gene therapy in $\mathrm{CF}$, but their modest results in clinical trials have slowed down their translation ${ }^{50}$. This limited success has been attributed to a low mucus penetration, as well as a moderate toxicity ${ }^{52}$. Thus, in 
our study, cationic liposomes were considered as a control formulation for the mucus penetration, bacteria interaction and biocompatibility studies.

Although PLA-g-PEG nanoparticles exhibited suitable physicochemical properties, they suffered from low encapsulation efficiency. We achieved $1.42 \mathrm{mg}$ of levofloxacin loading per $100 \mathrm{mg}$ of polymer, which was similar to levofloxacin loading in PLGA nanostructures ${ }^{15}(1-2.5 \% \mathrm{w} / \mathrm{w})$. This low amount was attributed to the nature of the drug, as more lipophilic drugs, such as amphotericin $\mathrm{B}^{38}$ and itraconazole ${ }^{37}$, have shown higher loadings in similar PLA-g-PEG nanoparticles. Further optimization could involve complexation with a counterion $^{14}$ or the use of the double emulsion technique ${ }^{16}$. Finally, anionic liposomes exhibited a higher levofloxacin encapsulation efficiency (11.92\%) and drug loading capacity (5.72\%) compared to polymeric nanoparticles (Table 1), although slightly lower than indicated in literature ${ }^{30,32}$. This suggests that the lipid bilayer and/or the aqueous environment is better suited to the amphipathic character of the levofloxacin as compared to the hydrophobic matrix of PLA- $g$-PEG.

\section{Levofloxacin release and efficiency}

We then compared the release of levofloxacin from polymeric nanoparticles and anionic liposomes to free levofloxacin. In vitro drug release showed similar levofloxacin release profiles for the free drug and for polymeric nanoparticles (Figure 1), suggesting that levofloxacin was weakly adsorbed onto the nanoparticle surface. Conversely, liposomes exhibited a prolonged release profile, releasing only $30 \%$ of their content after $24 \mathrm{~h}$ (Figure 1). The experiment was stopped after $72 \mathrm{~h} \mathrm{(34 \% )} \mathrm{and} \mathrm{the} \mathrm{results} \mathrm{suggested} \mathrm{a} \mathrm{slow}$ but continuous release, which could limit the systemic absorption of the drug, thereby limiting systemic side effects and extending its lung residence time ${ }^{25}$. Such a sustained release is consistent with levofloxacin release from microparticles for inhaled administration $^{29}$. In order to fine-tune the release profile, a physical mix of free and encapsulated drug can be envisioned, similar to the dual-release formulation of ciprofloxacin, Levoquin $^{\circledR}$, which has recently been used in clinical trials ${ }^{53}$. 


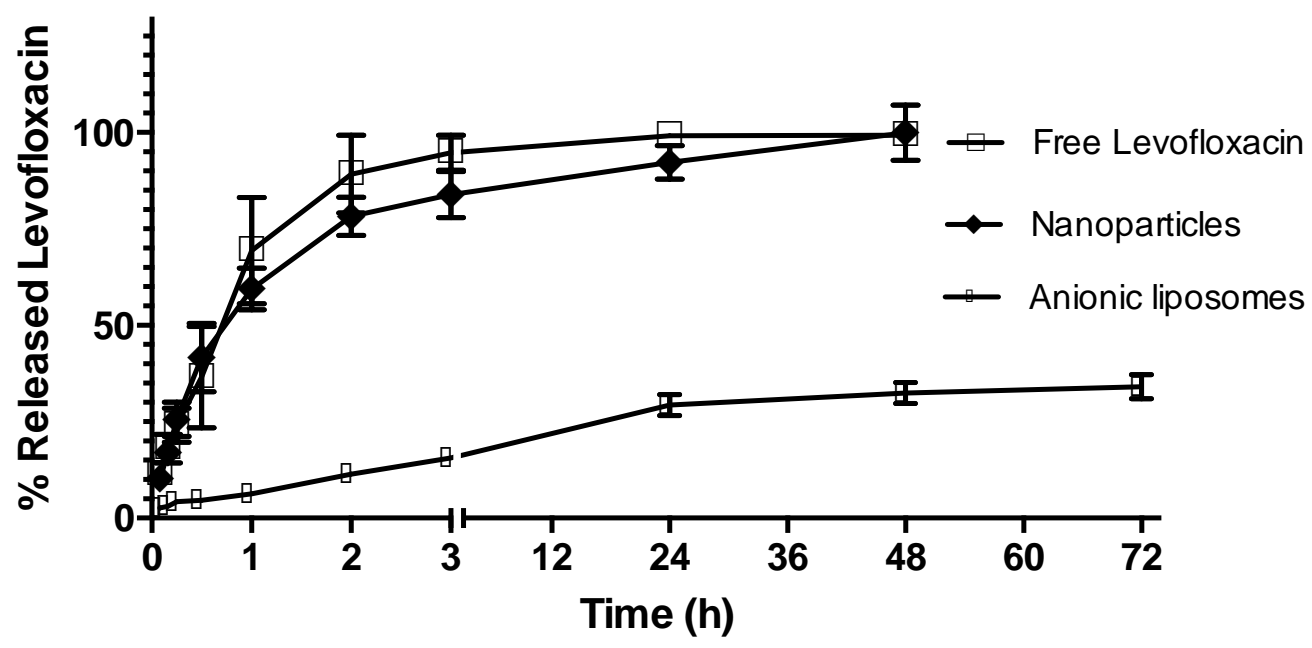

Figure 1. In vitro release kinetics of levofloxacin from polymeric nanoparticles $(\diamond)$ and anionic liposomes $(\bullet)$ as compared to free levofloxacin $(\square)\left(\mathrm{pH} 7.4,37^{\circ} \mathrm{C}\right)$; values are represented as means \pm S.D. of three independent experiments.

Antimicrobial activity was assessed in broth on four Pseudomonas aeruginosa strains isolated from CF patients, as well as on a control ATCC strain, by viability measurements ${ }^{54}$ (Figure S1). Two strains were mucoid, prone to forming biofilms, whereas two were non-mucoid strains, tending to form isolated colonies. Interestingly, mucoid isolates were sensitive to levofloxacin (MIC $\leq 2 \mu \mathrm{g} / \mathrm{mL}$, Table 2 ), which supports the use of levofloxacin for these strains, typically more resistant to destruction by the innate immune system ${ }^{23}$. In all conditions, encapsulated levofloxacin exhibited a similar minimal inhibitory concentration (MIC) to the free drug on all strains, regardless of their resistance. Encapsulation of levofloxacin did not reverse the resistance of non-mucoid strains (NM-01 and NM-02), as it has been reported for liposomal amikacin, for instance $^{21}$. This drug resistance may be due to overexpression of multi-drug resistance pumps, as found in $P$. aeruginosa ${ }^{55}$, or to altered DNA gyrase, reducing the affinity of fluoroquinolones for their substrate ${ }^{56}$. Polymeric nanoparticles exhibited a slightly higher MIC on 3 strains (M-01, NM-02, ATCC). Since immediate release of levofloxacin was observed during in vitro studies, these results suggest that polymeric nanoparticles partially impede levofloxacin activity. Coupled with their low encapsulation capability, 
these results suggest that PLA-g-PEG nanoparticles are an unsuitable formulation for levofloxacin pulmonary delivery.

Liposomes exhibited the same MIC on all strains for $24 \mathrm{~h}$ as well as $48 \mathrm{~h}$, suggesting that liposome encapsulation did not impede the therapeutic action of levofloxacin. In the literature, the encapsulation of antibiotics generally results in similar or lower MIC values than the free drug ${ }^{25}$. Only a very specific lipid composition was reported to improve the MIC on specific strains ${ }^{15,30}$. The wide range of available $P$. aeruginosa clinical strains, resulting from the extensive opportunistic ability of this species, might contribute to the variability of the results. Given that only $30 \%$ of drug molecules were released after $24 \mathrm{~h}$, this suggests an interaction between bacteria and levofloxacin-loaded liposomes, similar to the interaction reported for Arikace ${ }^{\mathrm{TM}^{21}}$, which promotes the efficacy of this formulation. It should be noted that blank formulations did not impact the viability of any of the strains (Figure S1).

Table 2. Minimal Inhibitory Concentration (MIC, $\mu \mathrm{g} / \mathrm{mL}$ ) of levofloxacin in aqueous solution, in liposomes, and in polymeric nanoparticles against Pseudomonas aeruginosa strains after $24 \mathrm{~h}$ and $48 \mathrm{~h}$. All tests were performed in triplicate for each strain (three independent replicates with three wells/condition). S: Sensitive (MIC $\leq 2 \mu \mathrm{g} / \mathrm{mL}$ ); $\mathrm{I}$ : Intermediate $(\mathrm{MIC}=4 \mu \mathrm{g} / \mathrm{mL}) ; \mathrm{R}:$ Resistant $(\mathrm{MIC} \geq 8 \mu \mathrm{g} / \mathrm{mL})$.

\begin{tabular}{|c|c|c|c|c|c|c|c|}
\hline \multirow[b]{2}{*}{ P. aeruginosa strain } & & \multicolumn{2}{|c|}{ Free Levofloxacin } & \multicolumn{2}{|c|}{$\begin{array}{l}\text { Anionic liposome } \\
\text { /Levofloxacin }\end{array}$} & \multicolumn{2}{|c|}{$\begin{array}{c}\text { Polymeric } \\
\text { nanoparticles } \\
\text { /Levofloxacin }\end{array}$} \\
\hline & & $24 \mathrm{~h}$ & $48 \mathrm{~h}$ & $24 \mathrm{~h}$ & $48 \mathrm{~h}$ & $24 \mathrm{~h}$ & $48 \mathrm{~h}$ \\
\hline \multirow{2}{*}{ Mucoid isolates } & M-01 & $0.5(\mathrm{~S})$ & 1 & 0.5 & 1 & 1 & 2 \\
\hline & M-02 & $0.5(\mathrm{~S})$ & 1 & 0.5 & 1 & 0.5 & 1 \\
\hline \multirow{2}{*}{ Non mucoid isolates } & NM-01 & $4(\mathrm{I})$ & 8 & 4 & 8 & 4 & 8 \\
\hline & NM-02 & $4(\mathrm{I})$ & 8 & 4 & 8 & 8 & 8 \\
\hline \multirow{2}{*}{ Control } & ATCC & \multirow{2}{*}{$0.5(\mathrm{~S})$} & \multirow{2}{*}{1} & \multirow{2}{*}{0.5} & \multirow{2}{*}{1} & \multirow{2}{*}{1} & \multirow{2}{*}{2} \\
\hline & 27853 & & & & & & \\
\hline
\end{tabular}

\section{Nanocarrier preclinical assessment for pulmonary administration Mucus stability and penetration}


One of the major barriers to lung delivery in CF patients is the mucus layer ${ }^{57}$, which has been reported as a major cause of failure for cationic liposomes ${ }^{52}$. Therefore, we assessed the stability and diffusion ability of anionic liposomes in artificial mucus relative to cationic liposomes, taken as a control. Anionic liposomes were stable in PBS and Simulated Interstitial Lung Fluid (SILF), since they maintained their hydrodynamic diameter and tight polydispersity (Table 3). In comparison, cationic liposomes exhibited a higher polydispersity in SILF (Table 3). In artificial mucus, proteins prevented accurate DLS measurement, so we examined colloidal kinetics using the Static Multiple Light Scattering (MSLS) technique ${ }^{41}$. The MSLS method detects size or concentration changes in specific zones of the sample by the transmitted and backscattered light intensities, which are in turn quantified by the turbiscan stability index (TSI) ${ }^{43}$. Hence, creaming, sedimentation, agglomeration, aggregation, and coalescence can be detected at a very early stage without dilution or stress, especially when DLS cannot give reliable results ${ }^{41}$. SILF and PBS media exhibited the lowest TSI after $20 \mathrm{~min}$, confirming the stability of these background media. The addition of anionic liposomes slightly increased these values, which were still lower than 1 , usually set as a reference stability level. Conversely, cationic liposomes strongly impacted the stability of PBS and SILF, with their TSI increasing to 5.3 and 1.9, respectively, confirming the DLS results (Table 3). In PBS, the backscattering plot exhibited a strong destabilization process which was not observed for anionic liposomes (Figures S2 \& S3). The high salt concentration might favor the coalescence of cationic liposomes, which was not detected by DLS but was visually observed after $24 \mathrm{~h}$ (Figure S4). In artificial mucus, the TSI of the suspension was already higher than the TSI observed in simple media due to the presence of surfactants and proteins, and demonstrated some variability in the measurement. The addition of anionic liposomes slightly decreased this variability, whereas cationic liposomes accentuated the destabilization, as shown by the higher TSI values (Table 3) and obvious precipitation after $24 \mathrm{~h}$ (Figure S4).

Table 3. Stability of liposomes in PBS (pH 7.4), SILF, artificial mucus, and their respective controls after $20 \mathrm{~min}$ at $37^{\circ} \mathrm{C}$, as measured by their hydrodynamic diameter and Turbiscan Stability Index (TSI). 


\begin{tabular}{llccc}
\hline & & $\mathrm{D}_{\mathrm{H}}(\mathrm{nm})$ & PdI & TSI \\
\hline PBS & & & 0.4 \\
& anionic liposomes & $148 \pm 2$ & $0.04 \pm 0.03$ & 0.9 \\
& cationic liposomes & $203 \pm 2$ & $0.13 \pm 0.01$ & 5.3 \\
\hline SILF & & & & 0.4 \\
& anionic liposomes & $157 \pm 7$ & $0.05 \pm 0.02$ & 0.9 \\
& cationic liposomes & $280 \pm 9$ & $0.21 \pm 0.01$ & 1.9 \\
\hline Mucus & & & & $1.0^{\mathrm{b}}$ \\
& anionic liposomes & $\mathrm{N} / \mathrm{A}^{\mathrm{a}}$ & $\mathrm{N} / \mathrm{A}^{\mathrm{a}}$ & 0.8 \\
& cationic liposomes & $\mathrm{N} / \mathrm{A}^{\mathrm{a}}$ & $\mathrm{N} / \mathrm{A}^{\mathrm{a}}$ & 1.6 \\
\hline
\end{tabular}

${ }^{a}$ Artifical mucus baseline exhibited micellar components of $155 \mathrm{~nm}$ and larger, which impeded the estimation of liposome diameter, since it was impossible to separate the nanoobjects by DLS.

${ }^{\mathrm{b}}$ Value of TSI normalized to 1.0, since mucus measurements exhibited a large variation of TSI values (0.6-1.8). TSI of anionic and cationic liposomes are reported as relative to their respective mucus background values.

The diffusion study across an artificial mucus layer confirmed these results. In the Transwell setup ${ }^{17}$, anionic liposomes were able to cross the mucus layer efficiently (Figure 2). After one hour, $80 \%$ of the maximal liposome recovery (measured without mucus) was observed in the receiver compartment, meaning that only $20 \%$ of the anionic liposomes were trapped in the mucus. This result is comparable to the diffusion of anionic liposomes through porcine mucus ${ }^{58}$ or in fresh patient sputum ${ }^{59}$. Obviously, the surface charge was a major determinant, as a cationic liposome formulation exhibiting the same hydrodynamic diameter (DOTAP/Chol, Table 1) hardly crossed the mucus layer (Figure 2), as noted in previous studies ${ }^{45}$. In addition, anionic liposomes maintained their hydrodynamic diameter after crossing the mucus barrier (Table 1), whereas the few cationic liposomes recovered in the receiver compartment significantly increased in size up to $503 \mathrm{~nm}$, and inversed their zeta potential to $-10.6 \mathrm{mV}$. This suggested the adsorption of mucin protein onto the cationic liposome surface, which immobilized the liposomes within the mucus layer, as previously reported ${ }^{17}$. We also monitored levofloxacin diffusion in artificial mucus. Levofloxacin displayed good diffusion ability through the mucus, either free or encapsulated, reaching 50\% diffusion after $24 \mathrm{~h}$ (Figure S5). Surprisingly, this finding revealed that levofloxacin might not require liposome technology for mucus penetration, unlike aminoglycosides ${ }^{60}$, while still requiring it for sustained release and to limit systemic exposure. Nevertheless, the diffusion experiments 
demonstrated that both free levofloxacin and anionic liposomes could be recovered following artificial mucus penetration.

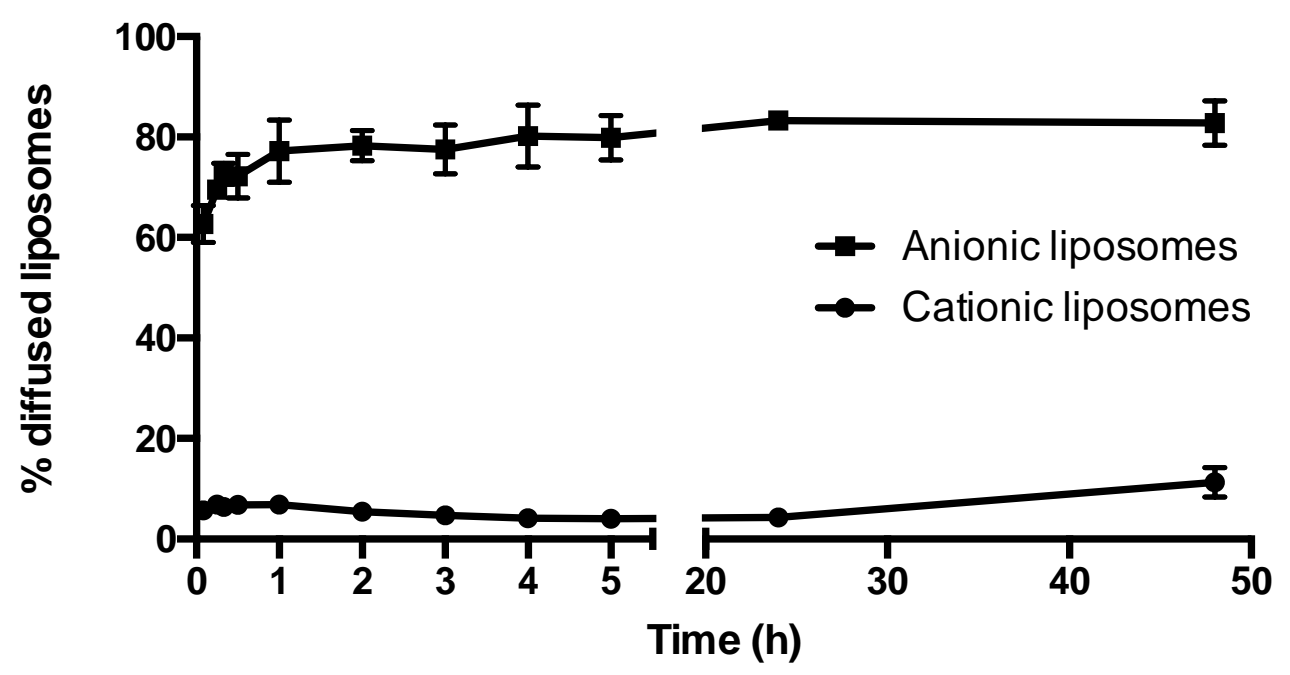

Figure 2. Diffusion of fluorescent anionic (•) and cationic ( $\boldsymbol{\square})$ liposomes through an

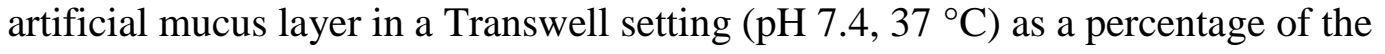
maximum fluorescence recovered from the diffusion of anionic liposomes in the absence of the mucus layer. Values are represented as means \pm S.D. of three independent experiments.

\section{Interaction with Pseudomonas aeruginosa membrane}

It has been reported that PEG shielding of nanoparticles could prevent them from interacting with cell membranes ${ }^{49}$. To investigate the possible interaction of liposomes with bacteria, we conducted flow cytometry analysis on Pseudomonas aeruginosa strains $^{61}$. Anionic liposomes significantly associated with $P$. aeruginosa, shifting their fluorescence to higher values in a dose-dependent manner (Figure 3A \& 3C). This trend was confirmed when analyzing the $P$. aeruginosa positive to rhodamine (Figure S6). At $67 \mu \mathrm{g} / \mathrm{mL}$ of lipids — the lipid amount required to encapsulate $8 \mu \mathrm{g} / \mathrm{mL}$ of levofloxacin (i.e. 1 to 8 times the MIC, depending on the strain, see Table 2) - the interaction was already significant, albeit lower than cationic liposomes, which also associated with $P$. aeruginosa (Figure 3B \& 3C, Figure S6) in agreement with literature ${ }^{62}$. This modest but significant interaction could be further optimized by tuning the lipid composition, for 
instance by improving the liposomal fluidity, already known to promote interactions with bacterial membranes ${ }^{25}$. Nevertheless, the dose-dependent interaction suggested that we found the right balance between stealth liposomes prone to crossing extracellular barriers, and adhesion properties favouring interactions with bacterial membranes.
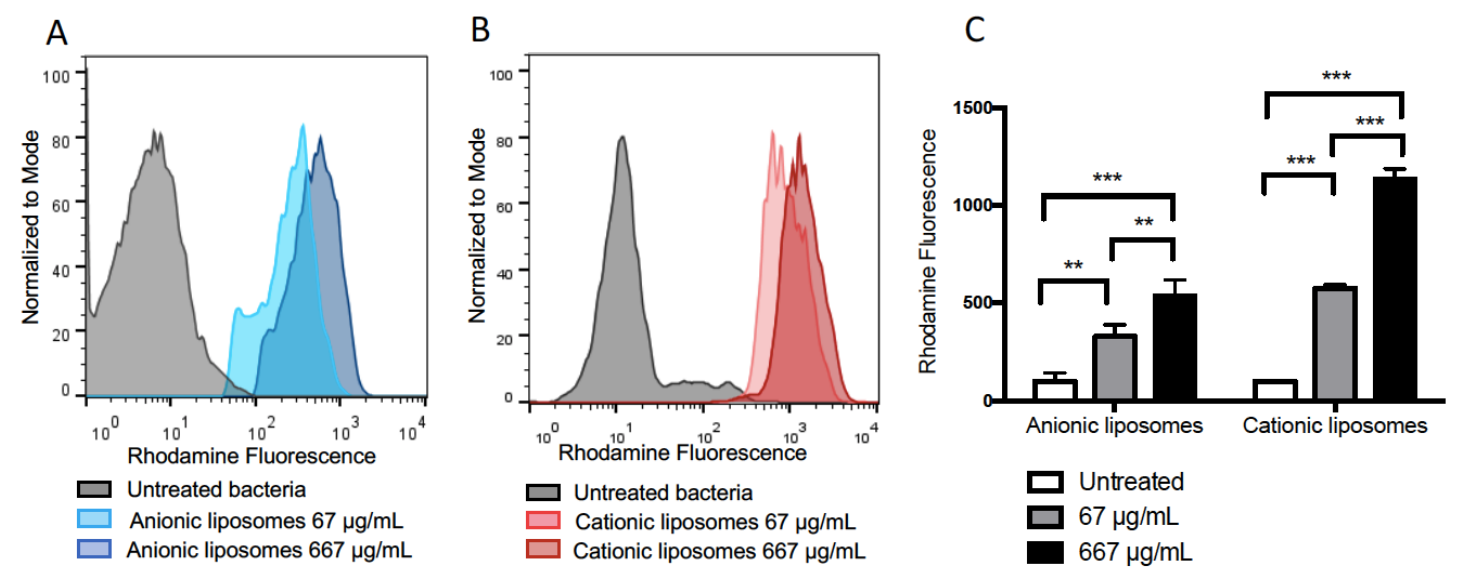

Figure 3. A) Flow cytometry histograms of $P$. aeruginosa incubated with increasing concentrations of fluorescent anionic liposomes $(67 \mu \mathrm{g} / \mathrm{mL}$ and $667 \mu \mathrm{g} / \mathrm{mL}$, corresponding to 1 to 10 times MIC). B) Flow cytometry histograms of $P$. aeruginosa incubated with increasing concentrations of fluorescent cationic liposomes $(67 \mu \mathrm{g} / \mathrm{mL}$ and $667 \mu \mathrm{g} / \mathrm{mL}, 1$ to 10 times MIC). C) Flow cytometry quantification of the geometric mean fluorescence intensity (normalized to the maximum fluorescence intensity) of positive $P$. aeruginosa incubated with increasing concentrations of fluorescent anionic or cationic liposomes $(\mathrm{n}=3) ; * * \mathrm{p}<0.01 ; * * * \mathrm{p}<0.001$.

\section{Biocompatibility with airway epithelial cells}

Liposome cytotoxicity was assessed using A549 adenocarcinomic lung epithelial cells. Since levofloxacin MIC values ranged from 1 to $8 \mu \mathrm{g} / \mathrm{mL}$ (Table 2), we tested levofloxacin formulations at concentrations up to $16 \mu \mathrm{g} / \mathrm{mL}$, corresponding to 2-16 times the MIC. Free and encapsulated levofloxacin were well tolerated by the epithelial cells, although slightly differently, but the viability remained higher than $80 \%$ after $48 \mathrm{~h}$ (Figure 4A). Given the prolonged release of this formulation and the low mucociliary clearance characteristic of $\mathrm{CF}^{3}$, higher residual concentrations of lipids may be reached in 
the lung. We therefore evaluated the viability of A549 cells with higher amounts of unloaded liposomes (Figure 4B). Anionic liposomes demonstrated good biocompatibility up to $700 \mu \mathrm{g} / \mathrm{mL}$, corresponding to $10-83$ times the MIC given a $11.91 \%$ levofloxacin loading (Table 1). This high biocompatibility was expected, as the components are already included in commercialized products ${ }^{63}$. In contrast, cationic liposomes significantly reduced the viability of epithelial cells, at concentrations as low as 400 $\mu \mathrm{g} / \mathrm{mL}$, which was also in agreement with literature ${ }^{64}$, and again endorsed the preferential use of anionic formulations.
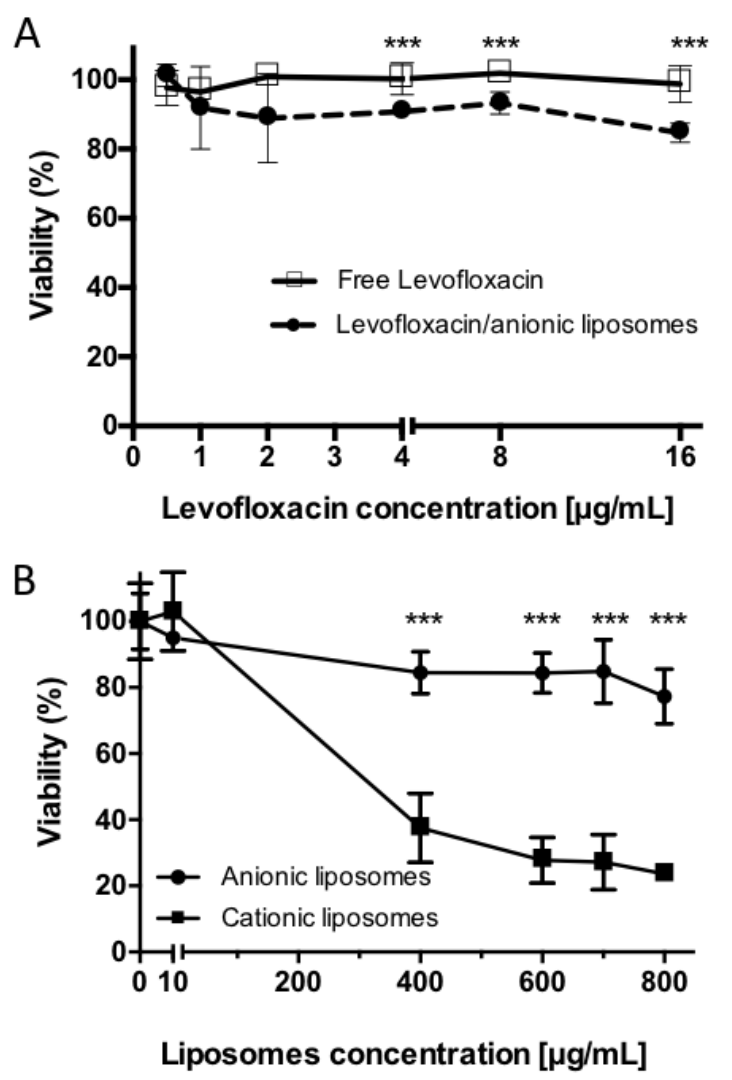

Figure 4. A) Viability of A549 cells after $48 \mathrm{~h}$ incubation with increasing concentrations of levofloxacin, either free $(\square)$ or encapsulated in anionic liposomes $(\bullet)(n=6 \pm$ S.D). B) Viability of A549 cells treated with increasing concentrations of cationic ( $\square)$ or anionic $(\bullet)$ unloaded liposomes after $48 \mathrm{~h}(\mathrm{n}=6 \pm$ S.D); $* * * \mathrm{p}<0.001$.

\section{Nebulization properties}


Pulmonary administration of liposomes could be achieved by dry powder inhalation, jet or mesh nebulization. Preclinical development of Arikace ${ }^{\mathrm{TM}}$ and Pulmaquin ${ }^{\circledR}$ demonstrated that liposomes required optimization to withstand the nebulization process ${ }^{24,65,66}$. Indeed, the tensioactive nature of the lipids could impact the size and stability of the droplets. Thus, anionic liposomes were further examined for their nebulization properties using the Next Generation Impactor coupled with a jet nebulizer (Figure S7). Nebulization only slightly impacted the liposome size (132 $\mathrm{nm}$ before and $156 \mathrm{~nm}$ after nebulization) and polydispersity ( 0.115 before and 0.167 after nebulization, Table S1), in agreement with previous literature on amikacin-loaded liposomes ${ }^{65}$. The emitted dose dose was higher for liposomal levofloxacin as compared to free levofloxacin $(1.96 \mathrm{mg} v s .1 .74 \mathrm{mg}$ ) for the same length of nebulization (Table 4). The size distribution showed the mean size of the nebulized droplets was between 2 and $5 \mu \mathrm{m}$, with a peak observed at $3.3 \mu \mathrm{m}$ (cup 4, Figure 5) for both free and liposomal levofloxacin. It is reported that aerosolized formulations should exhibit an aerodynamic diameter below $5 \mu \mathrm{m}$ in order to reach the deep part of the lung but greater than $1 \mu \mathrm{m}$ to avoid being exhaled ${ }^{23}$. Such particles are distributed into the alveolar spaces and correlate with a better response to treatment ${ }^{23}$. Anionic liposomes exhibited a low mass median aerodynamic diameter (MMAD) value (Table 4), meaning that $50 \%$ of the mass should reach capillaries of $2.43 \mu \mathrm{m}$ or lower (Figure S8), better than other nebulized liposomes ${ }^{67-69}$ and similarly to the stabilized liposomes reported by Manconi et $a l^{70}$. This MMAD value was similar for free and encapsulated levofloxacin, similarly to the Pulmaquin ${ }^{\circledR}$ preclinical studies with ciprofloxacin $^{68}$. The geometric standard variation (GSD) was lower for liposomes, suggesting a more homogeneous size distribution (Table 4). Interestingly, liposomal levofloxacin exhibited a significantly higher fine particle fraction (FPF) and respiratory fraction (RF) than free levofloxacin, suggesting a better deposition in the lower stages of the impactor, mimicking the deepest part of the respiratory tree (Table 4). This high respiratory fraction (94\%) demonstrated that levofloxacin-loaded anionic liposomes displayed suitable properties for nebulization and could reach the deep part of the lung, where the $P$. aeruginosa infection persists ${ }^{23}$. 


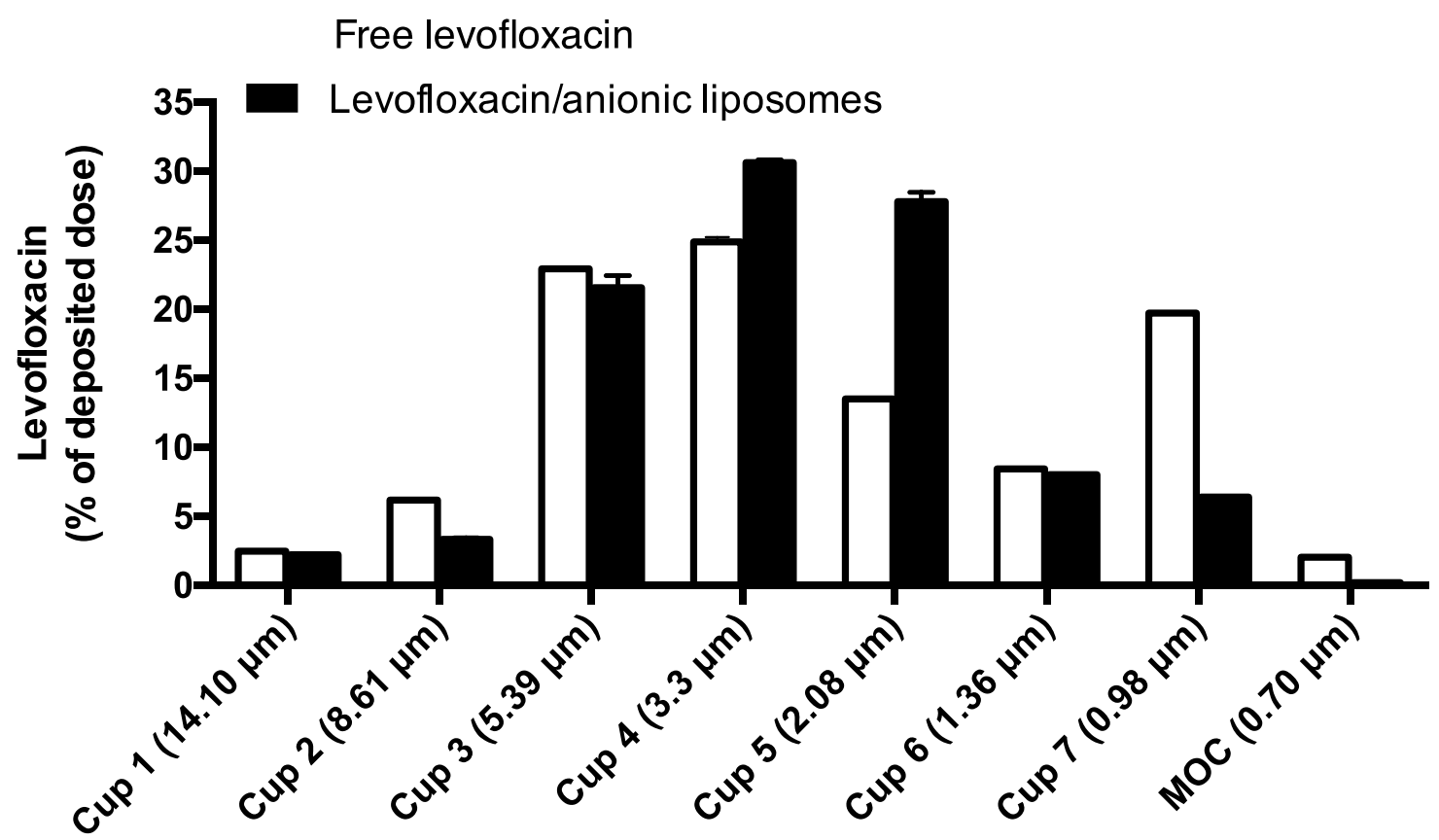

Figure 5. Size distribution obtained by NGI stage deposition of nebulized free or anionic liposome-loaded levofloxacin $(n=3, \pm S D)$.

Table 4. Aerodynamic particle characterization of nebulized formulations ( $n=3, \pm S D)$. $* * \mathrm{p}<0.01, * * * \mathrm{p}<0.001$

\begin{tabular}{lccccc}
\hline & $\mathrm{ED}(\mu \mathrm{g})$ & $\mathrm{MMAD}(\mu \mathrm{m})$ & GSD & FPF $(\%)$ & $\mathrm{RF}(\%)$ \\
\hline $\begin{array}{l}\text { Free levofloxacin } \\
\text { Levofloxacin/anionic } \\
\text { liposome }\end{array}$ & $1722 \pm 23$ & $2.23 \pm 0.03$ & $2.20 \pm 0.04$ & $4.40 \pm 0.02$ & $89.33 \pm 0.07$ \\
\hline
\end{tabular}

ED $($ emitted dose $)=$ total amount initially placed - amount remaining in the nebulizer chamber

MMAD (experimental mass median aerodynamic diameter particle size $)=$ size at $50 \%$ mass deposition

GSD (geometric standard deviation) $=\left(\frac{\text { size } x}{\text { size } y}\right)^{\frac{1}{2}}$ where $\left\{\begin{array}{l}x=\text { size at } 84 \% \text { mass deposition } \\ y=\text { size at } 16 \% \text { mass deposition }\end{array}\right.$

FPF $($ fine particle fraction $)=$ particles $\leq 5.39 \mu \mathrm{m}=\frac{\sum \text { Levo mass recovered from cups } 3 \text { to } 7}{\text { Levo mass initially introduced in nebulizer }} \times 100$

$\mathrm{RF}($ respirable fraction $)=$ particles $\leq 5.39 \mu \mathrm{m}=\frac{\sum \text { Levo mass recovered from cups } 3 \text { to } 7}{\sum \text { Levo mass recovered from cups } 1 \text { to } 7} \times 100$

\section{Conclusion}

In conclusion, we have compared several nanocarriers for levofloxacin encapsulation for the pulmonary treatment of Pseudomonas aeruginosa in CF patients. Cationic liposomes were not able to encapsulate any drug and were only considered as control formulations 
in this study. Polymeric nanoparticles exhibited suitable physicochemical properties but immediately released their payload and impeded antibiotic activity, and were therefore discarded for levofloxacin delivery. Finally, anionic liposomes exhibited sustained release and preserved the antimicrobial activity of levofloxacin. Thus, their clinical relevance for pulmonary administration was assessed in a stepwise manner. Anionic liposomes demonstrated a suitable colloidal stability in artificial mucus and were able to transport levofloxacin across an artificial mucus layer. Their surface properties allowed interaction with $P$. aeruginosa membrane, permitting delivery of the drug to the bacteria. This formulation did not show any toxicity to lung epithelial cells, even at high lipid concentrations. Finally, the liposomes were stable upon nebulization and their size distribution predicted deposition in the deeper part of the lungs. These results are in agreement with the clinical development of liposomes for ciprofloxacin (Pulmaquin $®$ ) and amikacin (Arikace ${ }^{\mathrm{TM}}$ ), and confirm the potential of liposomes for pulmonary administration of antibiotics.

Further optimization should focus on the lipid composition of liposomes to enhance encapsulation efficiency, bacterial interaction, and subsequently antimicrobial activity, while maintaining mucus-penetrating properties. Encapsulation efficiency could also be improved by using drug-specific aptamers, as we recently reported for tobramycin ${ }^{71}$. Dry powder formulation after freeze-drying could be envisaged to improve the long-term storage $^{72}$. Future experiments should include studies on structural stability upon storage, on the alveolar macrophage uptake and on the interaction with lung surfactant in order to warranty an efficient bench-to-clinics translation. Since $P$. aeruginosa is prone to biofilm formation in $\mathrm{CF}$ patients, penetration and antibacterial activity of this formulation in biofilms should be investigated, preferentially in the presence of mucus ${ }^{60}$. Further preclinical evaluation could involve more relevant in vitro models, such as a 3D lung epithelial model infected by $P$. aeruginosa ${ }^{73}$. Finally, the drug deposition and retention in the lungs should be determined in vivo using healthy mice ${ }^{29}$ before assessing the antimicrobial activity in mice with chronic $P$. aeruginosa infection ${ }^{74}$ or in CF models of lung infections, such as pigs and ferrets ${ }^{23,75}$.

\section{Acknowledgements}


The authors would like to thank Dr. Valerie Waters and Dr. Yvonne Yan at SickKids Hospital (Toronto, ON) for graciously providing the Pseudomonas aeruginosa species isolated from bronchoalveolar lavage fluids of cystic fibrosis patients. We also thank Florian Bernard for the flow cytometry analysis and Alexandre Melkoumov for statistical analysis.

\section{Financial support}

This work was achieved thanks to suppor of the faculty of pharmacy of University of Montreal, but did not receive any specific grant from funding agencies in the public, commercial, or not-for-profit sectors.

\section{Supplementary information}

Detailed results on $P$. aeruginosa viability, aerosolization setup and results, transmission, and backscattering plots of anionic and cationic liposomes, as well as visual observation of their colloidal stability and flow cytometry analysis are given in supplementary materials. The file also presents levofloxacin diffusion through an artificial mucus layer and additional fluorescent images of $P$. aeruginosa with anionic liposomes.

\section{References}

1. P. M. Farrell, The prevalence of cystic fibrosis in the European Union. $J$. Cystic Fibrosis. 2008;7:450-453

2. K. De Boeck, A. Zolin, H. Cuppens, H. V. Olesen and L. Viviani, The relative frequency of CFTR mutation classes in European patients with cystic fibrosis. $J$. Cystic Fibrosis. 2014;13:403-409

3. H. Matsui, B. R. Grubb, R. Tarran, S. H. Randell, J. T. Gatzy, C. W. Davis, et al., Evidence for Periciliary Liquid Layer Depletion, Not Abnormal Ion Composition, in the Pathogenesis of Cystic Fibrosis Airways Disease. Cell. 1998;95:1005-1015

4. P. A. Flume and D. R. VanDevanter, Clinical applications of pulmonary delivery of antibiotics. Adv. Drug Del. Rev. 2015;85:1-6

5. J. Emerson, M. Rosenfeld, S. McNamara, B. Ramsey and R. L. Gibson, Pseudomonas aeruginosa and other predictors of mortality and morbidity in young children with cystic fibrosis. Pediatr. Pulmonol. 2002;34:91-100

6. M. R. Kosorok, L. Zeng, S. E. H. West, M. J. Rock, M. L. Splaingard, A. Laxova, et al., Acceleration of lung disease in children with cystic fibrosis after Pseudomonas aeruginosa acquisition. Pediatr. Pulmonol. 2001;32:277-287

7. M. Klinger-Strobel, C. Lautenschläger, D. Fischer, J. G. Mainz, T. Bruns, L. Tuchscherr, et al., Aspects of pulmonary drug delivery strategies for infections in cystic fibrosis - where do we stand? Expert Opin. Drug Deliv. 2015;12:1351-1374 
8. P. A. Flume, P. J. Mogayzel, K. A. Robinson, C. H. Goss, R. L. Rosenblatt, R. J. Kuhn, et al., Cystic Fibrosis Pulmonary Guidelines. Am. J. Respir. Crit. Care Med. 2009; 180:802-808

9. M. E. Falagas, A. Michalopoulos and E. I. Metaxas, Pulmonary drug delivery systems for antimicrobial agents: facts and myths. Int. J. Antimicrob. Agents. 2010;35:101-106

10. P. Muralidharan, M. Malapit, E. Mallory, D. Hayes and H. M. Mansour, Inhalable nanoparticulate powders for respiratory delivery. Nanomed. Nanotechnol. Biol. Med. 2015;11:1189-1199

11. G. Costabile, I. d'Angelo, G. Rampioni, R. Bondì, B. Pompili, F. Ascenzioni, et al., Toward Repositioning Niclosamide for Antivirulence Therapy of Pseudomonas aeruginosa Lung Infections: Development of Inhalable Formulations through Nanosuspension Technology. Mol. Pharm. 2015;12:2604-2617

12. J. Duan, F. G. Vogt, X. Li, D. Hayes and H. M. Mansour, Design, characterization, and aerosolization of organic solution advanced spray-dried moxifloxacin and ofloxacin dipalmitoylphosphatidylcholine (DPPC) microparticulate/nanoparticulate powders for pulmonary inhalation aerosol delivery. Int. J. Nanomed. 2013;8:3489-3505

13. E. Lu, S. Franzblau, H. Onyuksel and C. Popescu, Preparation of aminoglycoside-loaded chitosan nanoparticles using dextran sulphate as a counterion. J. Microencaps. 2009;26:346-354

14. N. Günday Türeli, A. Torge, J. Juntke, B. C. Schwarz, N. Schneider-Daum, A. E. Türeli, et al., Ciprofloxacin-loaded PLGA nanoparticles against cystic fibrosis $\mathbf{P}$. aeruginosa lung infections. Eur. J. Pharm. Biopharm. 2017;117:363-371

15. W. S. Cheow, M. W. Chang and K. Hadinoto, The roles of lipid in anti-biofilm efficacy of lipid-polymer hybrid nanoparticles encapsulating antibiotics. Colloids Surf. Physicochem. Eng. Aspects. 2011;389:158-165

16. W. S. Cheow and K. Hadinoto, Lipid-polymer hybrid nanoparticles with rhamnolipid-triggered release capabilities as anti-biofilm drug delivery vehicles. Particuology. 2012;10:327-333

17. I. d'Angelo, B. Casciaro, A. Miro, F. Quaglia, M. L. Mangoni and F. Ungaro, Overcoming barriers in Pseudomonas aeruginosa lung infections: Engineered nanoparticles for local delivery of a cationic antimicrobial peptide. Colloids Surf. B. Biointerfaces. 2015;135:717-725

18. M. Alipour, Z. E. Suntres, R. M. Lafrenie and A. Omri, Attenuation of Pseudomonas aeruginosa virulence factors and biofilms by co-encapsulation of bismuth-ethanedithiol with tobramycin in liposomes. J. Antimicrob. Chemother. 2010;65:684-693

19. M. Alhariri and A. Omri, Efficacy of Liposomal Bismuth-EthanedithiolLoaded Tobramycin after Intratracheal Administration in Rats with Pulmonary Pseudomonas aeruginosa Infection. Antimicrob. Agents Chemother. 2013;57:569-578 20. M. Alipour, Z. E. Suntres, M. Halwani, A. O. Azghani and A. Omri, Activity and Interactions of Liposomal Antibiotics in Presence of Polyanions and Sputum of Patients with Cystic Fibrosis. PLoS ONE. 2009;4:e5724

21. P. Meers, M. Neville, V. Malinin, A. W. Scotto, G. Sardaryan, R. Kurumunda, et al., Biofilm penetration, triggered release and in vivo activity of inhaled liposomal 
amikacin in chronic Pseudomonas aeruginosa lung infections. J. Antimicrob. Chemother. 2008;61:859-868

22. M. Alhajlan, M. Alhariri and A. Omri, Efficacy and Safety of Liposomal Clarithromycin and Its Effect on Pseudomonas aeruginosa Virulence Factors. Antimicrob. Agents Chemother. 2013;57:2694-2704

23. I. d'Angelo, C. Conte, M. I. La Rotonda, A. Miro, F. Quaglia and F. Ungaro, Improving the efficacy of inhaled drugs in cystic fibrosis: Challenges and emerging drug delivery strategies. Adv. Drug Del. Rev. 2014;75:92-111

24. D. Cipolla, J. Blanchard and I. Gonda, Development of Liposomal Ciprofloxacin to Treat Lung Infections. Pharmaceutics. 2016;8:6

25. K. Hadinoto and W. S. Cheow, Nano-antibiotics in chronic lung infection therapy against Pseudomonas aeruginosa. Colloids Surf. B. Biointerfaces. 2014; 116:772-785

26. D. Azoicai and S. A. Antoniu, MP-376 (Aeroquin) for chronic Pseudomonas aeruginosa infections. Expert Opin. Invest. Drugs. 2013;22:267-276

27. S. Hadiya, X. Liu, W. Abd El-Hammed, M. Elsabahy and S. A. Aly, Levofloxacin-Loaded Nanoparticles Decrease Emergence of Fluoroquinolone Resistance in Escherichia coli. Microb. Drug Resist. 2018;24:1098-1107

28. M. Imran, M. R. Shah, F. Ullah, S. Ullah, A. M. Elhissi, W. Nawaz, et al., Sugarbased novel niosomal nanocarrier system for enhanced oral bioavailability of levofloxacin. Drug Deliv. 2016;23:3653-3664

29. G. A. Islan, M. E. Ruiz, J. F. Morales, M. L. Sbaraglini, A. V. Enrique, G. Burton, et al., Hybrid inhalable microparticles for dual controlled release of levofloxacin and DNase: physicochemical characterization and in vivo targeted delivery to the lungs. Journal of Materials Chemistry B. 2017;5:3132-3144

30. P. M. Furneri, M. Fresta, G. Puglisi and G. Tempera, Ofloxacin-Loaded

Liposomes: In Vitro Activity and Drug Accumulation in Bacteria. Antimicrob. Agents Chemother. 2000;44:2458-2464

31. P. Bagga, H. H. Siddiqui, J. Akhtar, T. Mahmood, M. Zahera and M. S. Khan, Gold Nanoparticles Conjugated Levofloxacin: For Improved Antibacterial Activity Over Levofloxacin Alone. Curr Drug Deliv. 2017;14:1114-1119

32. X. Zhang, P. Sun, R. Bi, J. Wang, N. Zhang and G. Huang, Targeted delivery of levofloxacin-liposomes for the treatment of pulmonary inflammation. J. Drug Targeting. 2009;17:399-407

33. A. Danion, I. Arsenault and P. Vermette, Antibacterial Activity of Contact Lenses Bearing Surface-Immobilized Layers of Intact Liposomes Loaded With Levofloxacin. J. Pharm. Sci. 2007;96:2350-2363

34. Ameeduzzafar, S. S. Imam, S. N. Abbas Bukhari, J. Ahmad and A. Ali, Formulation and optimization of levofloxacin loaded chitosan nanoparticle for ocular delivery: In-vitro characterization, ocular tolerance and antibacterial activity. Int. J.Biol. Macromol. 2018;108:650-659

35. S. K. Gaidukevich, Y. L. Mikulovich, T. G. Smirnova, S. N. Andreevskaya, G. M. Sorokoumova, L. N. Chernousova, et al., Antibacterial Effects of Liposomes Containing Phospholipid Cardiolipin and Fluoroquinolone Levofloxacin on Mycobacterium tuberculosis with Extensive Drug Resistance. Bull. Exp. Biol. Med. 2016; $160: 675-678$ 
36. A. C. Anselmo and S. Mitragotri, Nanoparticles in the clinic. Bioengineering \& Translational Medicine. 2016;1:10-29

37. S. Essa, F. Louhichi, M. Raymond and P. Hildgen, Improved antifungal activity of itraconazole-loaded PEG/PLA nanoparticles. J. Microencaps. 2012;0:1-13

38. V. Aoun, C. Duval, F. Pagniez, P. L. Pape, M. Raymond, G. Leclair, et al., Enhanced pulmonary administration of amphotericin B loaded in PEG-g-PLA nanoparticles: in vitro proof-of-concept and susceptibility against Candida spp and Aspergillus spp. J. Nanopharm. Drug Deliv. 2014;2:294-304

39. G. R. Bartlett, Phosphorus Assay in Column Chromatography. J. Biol. Chem. 1959;234:466-468

40. C. a. L. S. Institute, Reference Methods for Dilution Antimicrobial Susceptibility Tests for Bacteria That Grow Aerobically Document M07-A09. 2012;32:M07-A9

41. S. Daoud-Mahammed, P. Couvreur and R. Gref, Novel self-assembling nanogels: Stability and lyophilisation studies. Int. J. Pharm. 2007;332:185-191

42. O. R. Moss, Simulants of lung interstitial fluid. Health Phys. 1979;36:447-448

43. L. M. Perez-Mosqueda, L. A. Trujillo-Cayado, F. Carrillo, P. Ramirez and J. Munoz, Formulation and optimization by experimental design of eco-friendly emulsions based on d-limonene. Colloids Surf. B. Biointerfaces. 2015;128:127-31 44. H. Friedl, S. Dünnhaupt, F. Hintzen, C. Waldner, S. Parikh, J. P. Pearson, et al., Development and Evaluation of a Novel Mucus Diffusion Test System Approved by Self-Nanoemulsifying Drug Delivery Systems. J. Pharm. Sci. 2013;102:4406-4413 45. N. N. Sanders, E. Van Rompaey, S. C. De Smedt and J. Demeester, On the transport of lipoplexes through cystic fibrosis sputum. Pharm. Res. 2002;19:451-6 46. V. A. Marple, K. Olson Ba Fau - Santhanakrishnan, D. L. Santhanakrishnan K Fau - Roberts, J. P. Roberts Dl Fau - Mitchell, B. L. Mitchell Jp Fau - Hudson-Curtis and B. L. Hudson-Curtis, Next generation pharmaceutical impactor: a new impactor for pharmaceutical inhaler testing. Part III. extension of archival calibration to 15 L/min.

47. M. Fresta, S. Guccione, A. R. Beccari, P. M. Furneri and G. Puglisi, Combining molecular modeling with experimental methodologies: mechanism of membrane permeation and accumulation of ofloxacin. Biorg. Med. Chem. 2002;10:3871-3889 48. S. Essa, J. M. Rabanel and P. Hildgen, Characterization of rhodamine loaded PEG-g-PLA nanoparticles (NPs): Effect of poly(ethylene glycol) grafting density. Int. J. Pharm. 2011;411:178-187

49. S. Essa, J. M. Rabanel and P. Hildgen, Effect of polyethylene glycol (PEG) chain organization on the physicochemical properties of poly(d, l-lactide) (PLA) based nanoparticles. Eur. J. Pharm. Biopharm. 2010;75:96-106 50. E. W. F. W. Alton, D. K. Armstrong, D. Ashby, K. J. Bayfield, D. Bilton, E. V. Bloomfield, et al., Repeated nebulisation of non-viral CFTR gene therapy in patients with cystic fibrosis: a randomised, double-blind, placebo-controlled, phase $2 \mathrm{~b}$ trial. The Lancet. Respiratory Medicine. 2015;3:684-691

51. J. S. Suk, S. K. Lai, Y.-Y. Wang, L. M. Ensign, P. L. Zeitlin, M. P. Boyle, et al., The penetration of fresh undiluted sputum expectorated by cystic fibrosis patients by non-adhesive polymer nanoparticles. Biomaterials. 2009;30:2591-2597 
52. G. A. Duncan, J. Jung, J. Hanes and J. S. Suk, The Mucus Barrier to Inhaled Gene Therapy. Mol. Ther. 2016;24:2043-2053

53. D. J. Serisier, D. Bilton, A. De Soyza, P. J. Thompson, J. Kolbe, H. W. Greville, et al., Inhaled, dual release liposomal ciprofloxacin in non-cystic fibrosis bronchiectasis (ORBIT-2): a randomised, double-blind, placebo-controlled trial. Thorax. 2013;68:812-7

54. J. T. Seil and T. J. Webster, Antimicrobial applications of nanotechnology: methods and literature. Int. J. Nanomed. 2012;7:2767-2781

55. E. B. Hirsch and V. H. Tam, Impact of multidrug-resistant Pseudomonas aeruginosa infection on patient outcomes. Expert Rev. Pharmacoeconomics Outcomes Res. 2010;10:441-451

56. R. Y. Pelgrift and A. J. Friedman, Nanotechnology as a therapeutic tool to combat microbial resistance. Adv. Drug Del. Rev. 2013;65:1803-1815

57. N. Sanders, S. Desmedt, E. Vanrompaey, P. Simoens, F. Debaets and J. Demeester, Cystic Fibrosis Sputum. Am. J. Respir. Crit. Care Med. 2000;162:19051911

58. V. Bourganis, T. Karamanidou, E. Samaridou, K. Karidi, O. Kammona and C. Kiparissides, On the synthesis of mucus permeating nanocarriers. Eur. J. Pharm. Biopharm. 2015;97:239-49.

59. V. De Leo, S. Ruscigno, A. Trapani, S. Di Gioia, F. Milano, D. Mandracchia, et al., Preparation of drug-loaded small unilamellar liposomes and evaluation of their potential for the treatment of chronic respiratory diseases. Int. J. Pharm. 2018;545:378-388

60. T. F. Bahamondez-Canas, H. Zhang, F. Tewes, J. Leal and H. D. C. Smyth, PEGylation of Tobramycin Improves Mucus Penetration and Antimicrobial Activity against Pseudomonas aeruginosa Biofilms in Vitro. Mol. Pharm. 2018;15:1643-1652

61. K. Dillen, C. Bridts, P. Van der Veken, P. Cos, J. Vandervoort, K. Augustyns, et

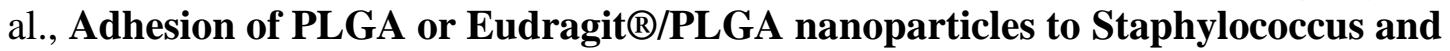
Pseudomonas. Int. J. Pharm. 2008;349:234-240

62. Z. Drulis-Kawa, A. Dorotkiewicz-Jach, J. Gubernator, G. Gula, T. Bocer and W. Doroszkiewicz, The interaction between Pseudomonas aeruginosa cells and cationic PC:Chol:DOTAP liposomal vesicles versus outer-membrane structure and envelope properties of bacterial cell. Int. J. Pharm. 2009;367:211-219

63. P. van Hoogevest and A. Wendel, The use of natural and synthetic phospholipids as pharmaceutical excipients. Eur. J. Lipid Sci. Technol. 2014;116:1088-1107

64. M. Roursgaard, K. B. Knudsen, H. Northeved, M. Persson, T. Christensen, P. E. $\mathrm{K}$. Kumar, et al., In vitro toxicity of cationic micelles and liposomes in cultured human hepatocyte (HepG2) and lung epithelial (A549) cell lines. Toxicol. In Vitro. 2016;36:164-171

65. Z. Li, Y. Zhang, W. Wurtz, J. K. Lee, V. S. Malinin, S. Durwas-Krishnan, et al., Characterization of nebulized liposomal amikacin (Arikace) as a function of droplet size. J. Aerosol Med. Pulm. Drug Deliv. 2008;21:245-54 
66. D. Cipolla, B. Shekunov, J. Blanchard and A. Hickey, Lipid-based carriers for pulmonary products: Preclinical development and case studies in humans. $A d v$. Drug Del. Rev. 2014;75:53-80

67. H. R. Desu, L. A. Thoma and G. C. Wood, Nebulization of Cyclic ArginineGlycine-(D)-Aspartic Acid-Peptide Grafted and Drug Encapsulated Liposomes for Inhibition of Acute Lung Injury. Pharm. Res. 2018;35:94

68. H. X. Ong, D. Traini, D. Cipolla, I. Gonda, M. Bebawy, H. Agus, et al., Liposomal nanoparticles control the uptake of ciprofloxacin across respiratory epithelia. Pharm. Res. 2012;29:3335-46

69. I. d'Angelo, G. Costabile, E. Durantie, P. Brocca, V. Rondelli, A. Russo, et al., Hybrid Lipid/Polymer Nanoparticles for Pulmonary Delivery of siRNA:

Development and Fate Upon In Vitro Deposition on the Human Epithelial Airway Barrier. J Aerosol Med Pulm Drug Deliv. 2018;31:170-181

70. M. Manconi, M. L. Manca, D. Valenti, E. Escribano, H. Hillaireau, A. M. Fadda, et al., Chitosan and hyaluronan coated liposomes for pulmonary administration of curcumin. Int. J. Pharm. 2017;525:203-210

71. K. Plourde, R. M. Derbali, A. Desrosiers, C. Dubath, A. Vallee-Belisle and J. Leblond, Aptamer-based liposomes improve specific drug loading and release. $J$. Controlled Release. 2017;251:82-91

72. L. Willis, D. Hayes, Jr. and H. M. Mansour, Therapeutic liposomal dry powder inhalation aerosols for targeted lung delivery. Lung. 2012;190:251-62

73. A. Crabbé, Y. Liu, N. Matthijs, P. Rigole, C. De La Fuente-Nùñez, R. Davis, et al., Antimicrobial efficacy against Pseudomonas aeruginosa biofilm formation in a three-dimensional lung epithelial model and the influence of fetal bovine serum. Sci. Rep. 2017;7:43321

74. I. Kukavica-Ibrulj and R. C. Levesque, Animal models of chronic lung infection with Pseudomonas aeruginosa: useful tools for cystic fibrosis studies. Lab. Anim. 2008;42:389-412

75. N. W. Keiser and J. F. Engelhardt, New animal models of cystic fibrosis: what are they teaching us? Curr. Opin. Pulm. Med. 2011;17:478-483 